\title{
Note on the Digital Archive
}

The original audiotapes and other research materials related to Robert Penn Warren's Who Speaks for the Negro? are held by the University of Kentucky and the Yale University Libraries. In cooperation with these institutions, the Robert Penn Warren Center for the Humanities and the Jean and Alexander Heard Libraries at Vanderbilt University created a complete digital archive, which is fully searchable and available to the public at http://whospeaks.library.vanderbilt.edu/.

The Who Speaks for the Negro? Digital Archive consists of the original reel-to-reel recordings that Warren compiled for each of his interviewees. In addition, it incorporates all print materials - transcripts, letters, book reviews, and more - related to the project. The archive also includes interviews that are not in the book (for example, a conversation with Septima Clark). Readers of Who Speaks for the Negro? are invited to listen to the original interviews and peruse the related documents in order to deepen their understanding of the project, its characters, and the historical period from which it emerged.

Mona Frederick, Executive Director Robert Penn Warren Center for the Humanities Vanderbilt University 
This page intentionally left blank 